\title{
Efeito da mesogeometria da broca e das condições de lubrirrefrigeração sobre o acabamento do furo em aço ARBL DIN S700MC
}

\section{Effect of drill meso-geometry and lubri -cooling conditions on the finish hole in DIN S700MC HSLA steel}

Luiz Eduardo da Silva ${ }^{1}$, Luiz Airton Consalter ${ }^{1}$, William Haupt ${ }^{1}$ André João de Souza

\footnotetext{
${ }^{1}$ Universidade de Passo Fundo, Laboratório de Usinagem, Passo Fundo, Rio Grande do Sul, Brasil.

${ }^{2}$ Universidade Federal do Rio Grande do Sul, Laboratório de Automação em Usinagem, Porto Alegre, Rio Grande do Sul, Brasil.

e-mail: 1silva@upf.br, lac@upf.br,williamhaupt@upf.br,ajsouza@ufrgs.br
}

\section{RESUMO}

O trabalho apresenta um estudo sobre os efeitos decorrentes da modificação da mesogeometria de uma broca helicoidal de metal-duro com revestimento de TiAlN sobre o acabamento superficial do aço de alta resistência e baixa liga DIN S700MC utilizando diferentes condições de aplicação de fluidos lubrirrefrigerantes (em abundância, em mínima quantidade e a seco). Para tanto, foram consideradas como variáveis de resposta a rugosidade do furo, o dimensional da rebarba gerada e a camada afetada pelo calor. Os resultados mostram que a utilização da broca com mesogeometria alterada gerou uma redução dos valores de rugosidade, maior valor dimensional da rebarba gerada e maiores valores de modificação microestrutural pelo calor. Com relação aos meios lubrirrefrigerantes, os resultados de rugosidade não foram influenciados pelas diferentes condições de aplicação; o fluido em abundância, juntamente com a broca sem modificação, apresentou os menores valores de rebarba; não houve variações expressivas entre a aplicação do fluido em abundância e em mínima quantidade na análise da camada afetada pelo calor.

Palavras-chave: furação de aço ARBL; mínima quantidade de lubrificante; mesogeometria da broca.

\section{ABSTRACT}

This paper presents an investigation on the behavior and effect of the machining process by drilling through a DIN S700MC steel alloy, correlating the preparation of cutting-edge geometry with different coolinglubrication conditions, and focusing on the surface finishing of the machined part. In this context, experimental tests were performed with different cooling-lubrication systems (abundance, MQL, and dry) using solid carbide twist drills, coated with titanium aluminum nitride, with or without meso-geometry preparation (roundings). As response variables were assessed the texture (roughness), the layer affected by heat throughout the hole and burr dimensional profiles. The results indicate a significant reduction of roughness values when using the rounding drill flank, face and guides. Statistically, this result was not influenced by the different cooling-lubrication systems. Regarding burr dimension generated by the process, the tool with no mesogeometry preparation presented the same values along with the application of fluid in abundance (emulsion). In the analysis of the layer affected by heat, the tool with meso-geometry preparation presented lower values of the affected layer (microstructure change) and, statistically, there were no significant variations between the application of fluid in abundance and with MQL.

Keywords: HSLA steel drilling; minimum quantity lubrication; drill meso-geometry.

\section{INTRODUÇÃO}

Atualmente há uma forte cobrança e uma grande expectativa em relação à redução dos problemas causados direta e indiretamente ao meio ambiente tais como o alto consumo de combustível, a emissão de $\mathrm{CO}_{2}$ e o uso 
de fluidos de corte na indústria metal-mecânica. Neste sentido, algumas ações preventivas estão sendo pesquisadas visando reduzir o peso dos componentes mecânicos e minimizar (ou eliminar) o fluido de corte [1]. A utilização de aços de alta resistência e baixa liga (ARBL) é uma delas.

Os aços ARBL têm apresentado resultados satisfatórios em relação à resistência/peso de estruturas metálicas quando comparados com aços convencionais. Dependendo da composição química, esses podem ser até 30\% mais leves, mas com a mesma resistência mecânica, pois utilizam chapas menos espessas, o que contribui para a redução de peso dos componentes e, consequentemente, para a redução do consumo de combustível e de outros fatores que são intrínsecos a esta condição [2].

Alguns ramos da indústria estão utilizando essas ligas, como alternativa de construção de componentes em navios, guindastes, automóveis, plataformas de petróleo e linhas de transmissão de óleo e gás. Isso incrementa a demanda de usinagem deste material e, consequentemente, o devido conhecimento sobre o comportamento durante o corte do mesmo [3]. No entanto, apesar da tendência pela utilização dos aços ARBL, poucos trabalhos científicos retratam o seu comportamento durante o processo de usinagem por furação.

KLOCKE [4] aponta algumas particularidades da furação, o qual a diferencia de outros processos de usinagem, tais como: variação da velocidade de corte do centro da broca (igual à zero) para a periferia (valor máximo), dificuldade no transporte do cavaco para fora do furo, distribuição inadequada de calor na região de corte, desgaste acentuado das quinas da broca e atrito das guias/parede do furo.

Essas características da furação podem gerar elevadas temperaturas nas interfaces broca/peça e broca/cavaco, podendo ocasionar zonas de material aderido sobre a superfície usinada, variações geométricas e defeitos metalúrgicos na região superficial e subsuperficial da peça [5].

Fabricantes de brocas e centros de pesquisas têm buscado soluções para aumentar a vida útil das ferramentas de corte, como modificações geométricas e alterações nos revestimentos. Em alguns casos, a modificação da mesogeometria (arredondamento ou chanframento dos gumes) tem demostrado resultados satisfatórios. $\mathrm{O}$ arredondamento objetiva reduzir defeitos nas superfícies da broca causados pelos microlascamentos remanescentes do processo de fabricação da ferramenta, podendo proporcionar uma furação mais estável (reduzindo as vibrações), uma melhor redistribuição das forças de usinagem e alterações no fluxo de cavaco. Isto pode possibilitar um incremento dos parâmetros de corte (redução dos tempos de processo) e maior estabilidade durante a usinagem. Tais modificações refletem-se na qualidade superficial da peça usinada [6-8].

Contudo, necessita-se de uma caracterização desta mesogeometria modificada, a qual pode ser realizada por meio de medições na própria ferramenta. No caso do arredondamento dos gumes da broca, faz-se necessário uma medição nas intersecções entre as distâncias tangentes da superfície de folga e saída e seus respectivos pontos de deslocamento. Esta geometria é classificada pelo seu fator de forma $\mathrm{K}$ que relaciona a inclinação da mesogeometria em relação aos ângulos de saída $(\gamma)$ e de folga $(\alpha)$. Sejam S $\gamma$ e $S \alpha$ os comprimentos dos respectivos gumes. O fator de forma é dado por $\mathrm{K}=\mathrm{S} \gamma / \mathrm{S} \alpha$. Se $\mathrm{K}=1$, a mesogeometria é simétrica em relação ao gume; quando $\mathrm{K}>1$, a mesogeometria está inclinada na direção da superfície de saída; para $\mathrm{K}<1$, a mesogeometria está inclinada na direção da superfície de folga [8-9].

Entretanto, VENTURA e DENKENA [10] citam que o arredondamento dos gumes pode aumentar a deformação do cavaco à frente do gume, aumentar a temperatura, os esforços de corte e a rugosidade da peça.

Outro tema pesquisado refere-se a tipos e formas de aplicação de fluidos de corte. Sabe-se dos seus benefícios para os processos de usinagem. Porém, isso traz inconvenientes associados à usinagem relativos a aspectos ecológicos (preservação do meio ambiente), econômicos (custos de compra e manutenção) e sanitários (saúde dos trabalhadores). Economicamente, seu uso pode aumentar os custos globais de produção em até $17 \%$. A aplicação de fluidos biodegradáveis, semissintéticos, sistemas para mínima quantidade de lubrificante (MQL) e usinagem a seco são algumas possibilidades para a redução dos problemas citados [11-13].

Assim, o trabalho visa investigar os efeitos da alteração da mesogeometria da broca (arredondamento dos gumes no flanco, na face, nas guias e nas quinas), correlacionando-a com diferentes formas de aplicação de meios lubrirrefrigerantes (abundância, MQL e a seco) sobre o acabamento das peças usinadas. Esta investigação envolve a avaliação da rugosidade (textura), da dimensão da rebarba gerada, da microdureza superficial e da modificação metalúrgica da camada afetada pelo calor.

\section{MATERIAIS E MÉTODOS}

\subsection{Caracterização do material-base}


O material utilizado neste trabalho foi uma chapa de aço DIN S700MC, com nome comercial de OPTIM 700MC Plus, da empresa SSAB/Ruukki, Finlândia. Este é um aço de alta resistência e baixa liga, com laminação termomecânica e resfriamento controlado. A sua composição química está mostrada na Tabela 1.

Tabela 1: Composição química do Aço DIN S700MC utilizado (em \% massa).

\begin{tabular}{c|c|c|c|c|c|c|c|c}
\hline $\mathbf{C}$ & $\mathbf{M n}$ & $\mathbf{S i}$ & $\mathbf{T i}$ & $\mathbf{N b}$ & $\mathbf{A l}$ & $\mathbf{V}$ & $\mathbf{P}$ & $\mathbf{S}$ \\
\hline 0,056 & 1,790 & 0,180 & 0,102 & 0,064 & 0,047 & 0,011 & 0,009 & 0,004 \\
\hline
\end{tabular}

De modo a permitir a caracterização do material-base, seis corpos de prova foram fabricados segundo as recomendações descritas na norma ASTM E8M e submetidos a ensaios de tração no Núcleo de Tecnologia Mecânica (NTM) da Universidade de Passo Fundo (UPF). Utilizou-se para isso uma máquina universal de ensaios mecânicos Schenk com capacidade de 200 kN, com software Panatec 4.1 para geração da curva tensão/deformação. Os ensaios foram realizados visando avaliar os valores da tensão máxima, da tensão de escoamento e o alongamento final.

Para determinar a dureza média do material-base, foram realizadas seis leituras em cada corpo de prova conforme a norma de referência ASTM E384. O ensaio de dureza Vickers foi realizado no NTM-UPF utilizando o durômetro Heckert HPO 250 com carga de $5 \mathrm{kgf}$.

Para análise microestrutural, as amostras foram preparadas conforme recomendação da norma ASTM E3. No caso, foram tomados 20 pontos em regiões distintas de cada amostra. A avaliação da distribuição e da morfologia das inclusões não metálicas foi realizada no material-base sem ataque químico utilizando um microscópio óptico ZEISS modelo AXION A1. Para revelação da microestrutura, a amostra passou por um ataque químico, o qual seguiu as orientações da norma ASTM E407. A avaliação sobre a composição química das inclusões foi realizada no microscópio eletrônico de varredura (MEV) TESCAN modelo VEGA LM 3 utilizando a técnica de espectrometria de energia dispersiva de raios-X (EDS) da marca OXFORD Instruments. As análises seguiram recomendações da norma ASTM E45.

\subsection{Equipamentos e ferramental}

O processo de furação do aço ARBL DIN S700MC foi realizado em um centro de usinagem vertical ROMI Modelo D800, com rotação máxima de $7500 \mathrm{rpm}$ e potência de $15 \mathrm{~kW}$.

Os corpos de prova para a usinagem foram preparados com dimensões de $220 \mathrm{~mm}$ de comprimento, $15 \mathrm{~mm}$ de largura e $11 \mathrm{~mm}$ de espessura, fixos paralelamente à mesa do centro de usinagem.

As brocas utilizadas são da marca Titex Plus modelo A3265TFL Alpha 2 (DIN 6537K), com diâmetro $\mathrm{D}=8,5 \mathrm{~mm}$, substrato da classe $\mathrm{K} 30 \mathrm{~F}$ (microgrãos), inteiriça de metal-duro, revestimento de nitreto de titânio-alumínio (TiAlN), haste com diâmetro de $10 \mathrm{~mm}$ e comprimento de $40 \mathrm{~mm}$, ângulo de folga $\alpha=10^{\circ}$, ângulo de ponta $\sigma=140^{\circ}$, ângulo de hélice $\delta=25^{\circ}$ e afiação cruzada. Duas mesogeometrias foram utilizadas: sem arredondamento dos gumes (broca A) e com arredondamento (broca B). A Figura 1 mostra as imagens obtidas com auxílio do microscópio eletrônico de varredura (MEV) Tescan modelo Vega LM3. 


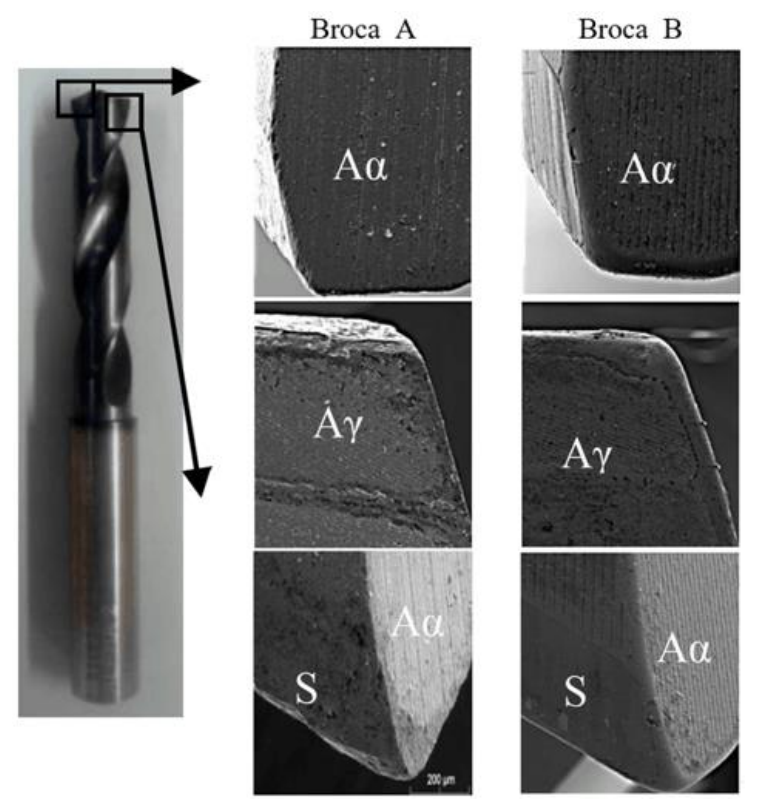

Figura 1: Imagens das brocas obtidas com MEV (ampliação 500x): face (A $\gamma)$, flanco $(\mathrm{A} \alpha)$ e guia secundária (S).

O fluido utilizado para o sistema MQL foi o Vascomill MKS 22 da marca Blaser Swisslube, à base de ésteres vegetais, não miscíveis em água, viscosidade a $40{ }^{\circ} \mathrm{C}$ de $22 \mathrm{~mm}^{2} / \mathrm{s}$ e densidade de $0,905 \mathrm{~g} / \mathrm{cm}^{3}$. $\mathrm{O}$ pulverizador utilizado foi um sistema aspersor externo da empresa Quimatic modelo IV. A pressão de trabalho utilizada foi de 5 bar com vazão de $50 \mathrm{ml} / \mathrm{h}$.

No sistema com fluido em abundância foi utilizado o óleo Castrol Superedge 6552, biodegradável, semissintético, isento de cloro, nitrito e fenóis, em uma solução 1:12 com vazão aproximada de 350 1/h.

\subsection{Procedimento experimental}

Realizaram-se 12 furos para cada condição analisada (duas brocas e três meios lubrirrefrigerantes), totalizando 72 furos. Os parâmetros de corte foram definidos para todos os furos utilizando rotação $\mathrm{n}=2500 \mathrm{rpm}$ e velocidade de avanço $\mathrm{v}_{\mathrm{f}}=250 \mathrm{~mm} / \mathrm{min}$. A estratégia utilizada para furação foi em cheio, sem furo de centro e passante. As distâncias entre furos foram de $17 \mathrm{~mm}(2 \cdot \mathrm{D})$ e a relação comprimento/diâmetro (L/D) do furo foi igual a $11 / 8,5 \cong 1,3$.

Para avaliação das variáveis de saída (rugosidade, dimensionamento da rebarba, microdureza e camada afetada pelo calor), as amostras foram seccionadas no sentido transversal à parede do furo utilizando uma máquina de eletroerosão a fio AgieCharmilles modelo Cut 200 (fio com 0,25 mm de diâmetro).

Os valores de rugosidade média $\left(\mathrm{R}_{\mathrm{a}}\right)$ foram avaliados com um rugosímetro portátil Mitutoyo modelo SJ 410 com resolução de $0,01 \mu \mathrm{m}$, raio de ponta do apalpador de $5 \mu \mathrm{m}$ em diamante. Foi utilizado um comprimento de amostragem (cut-off) de $0,8 \mathrm{~mm}$ e um comprimento de avaliação de $4 \mathrm{~mm}$. As leituras foram realizadas na entrada e na saída do furo, pois o comprimento de avalição (4 mm) na entrada e saída percorre praticamente toda a extensão (espessura) da peça de $11 \mathrm{~mm}$.

As imagens da textura das paredes dos furos, a medição da rebarba gerada e a medição da camada afetada pelo calor foram realizadas com o auxílio do MEV Tescan Vega LM3.

Para avaliação qualitativa das superfícies (textura) na parede dos furos, foi adotado um procedimento de análise por regiões (entrada, meio e saída). As imagens foram captadas a 1,0 mm, 5,5 mm e $10 \mathrm{~mm}$ da borda de entrada, conforme Figura 2. 


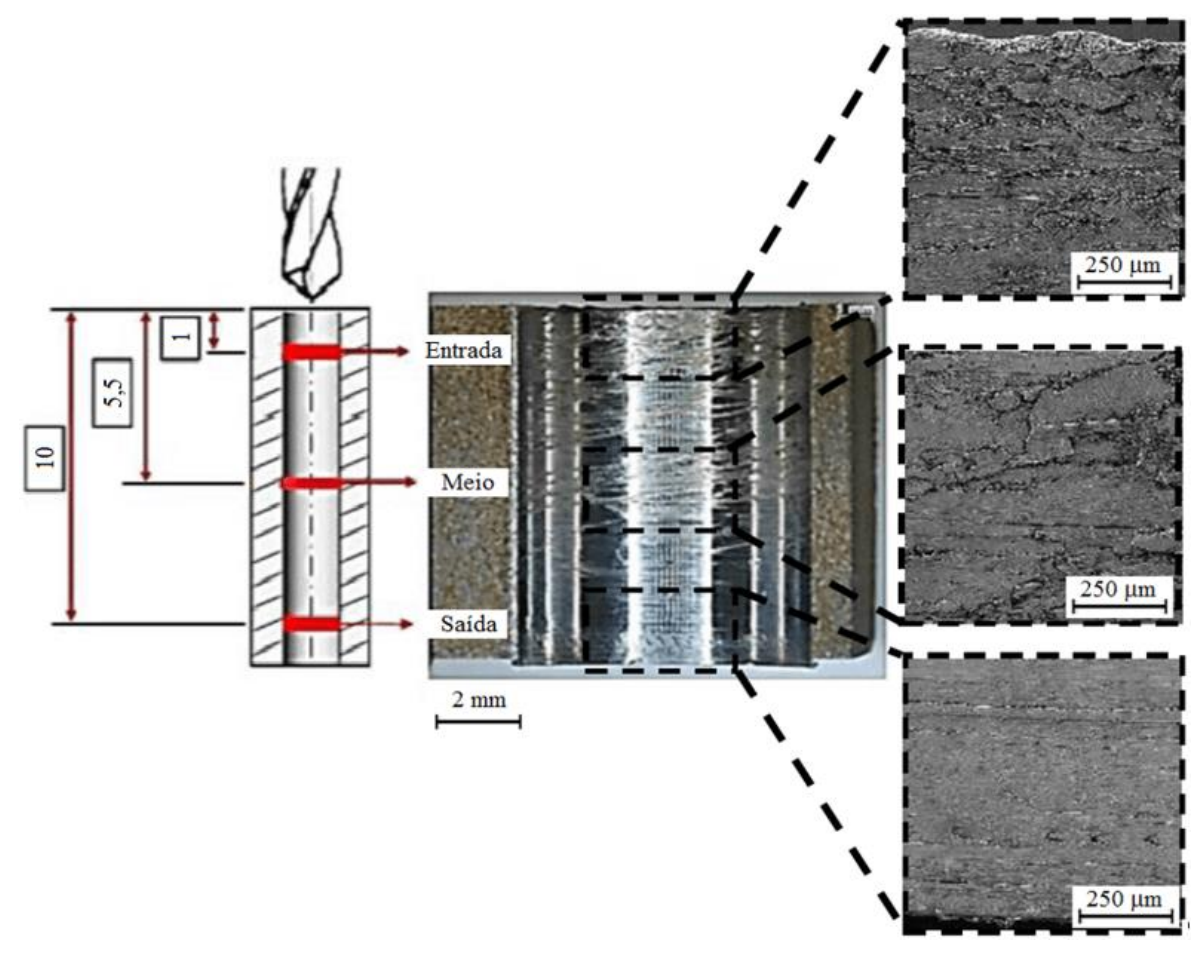

Figura 2: Representação das regiões de análise qualitativa das texturas dos furos.

Para observação da dimensão da rebarba na saída do furo gerada pelo processo de furação foi estabelecido o seguinte critério: medição de altura e espessura da rebarba. Para tanto, foram criadas linhas de referência para orientação das medidas. As medições foram realizadas com o uso do software de medição do próprio MEV através da ferramenta Measurement. As referências estão ilustradas na Figura 3.

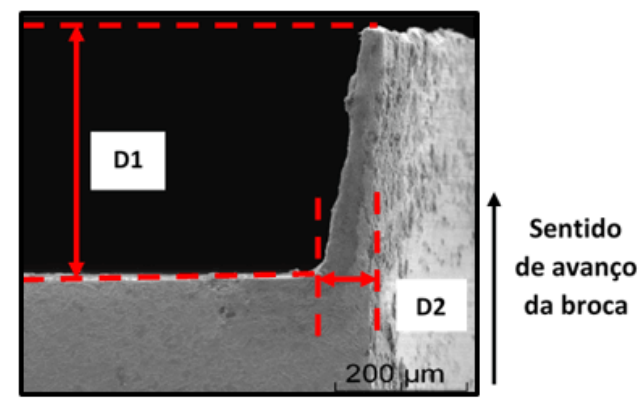

Figura 3: Esquema de orientação das medidas realizadas na rebarba gerada na saída dos furos: altura da rebarba (D1) e espessura da raiz (D2).

Para a avaliação largura da camada afetada pelo calor (CAC), as amostras passaram por procedimentos micrográficos de preparação (lixamento, polimento e ataque químico com Nital 2\%). As medições forma feitas com o auxílio do MEV e manteve-se o mesmo critério de análise por regiões (entrada, meio e saída) de cada um dos 72 furos, totalizando 216 micrografias.

O experimento foi conduzido em um Planejamento Experimental Fatorial 3x2 com Análise de Variância (ANOVA) no nível confiança de 95\% para comparação das médias utilizando o software Minitab®17.

\section{RESULTADOS}

\subsection{Material do corpo de prova}

Os resultados dos ensaios de tração dos seis corpos de prova do aço DIN S700MC, com uma confiança de $95 \%$, foram: resistência a tração $(850,0 \pm 14,7) \mathrm{MPa}$, tensão de escoamento $(670,0 \pm 13,5) \mathrm{MPa}$ e alongamento $(23 \pm 1) \%$. Os corpos de prova foram também avaliados quanto à dureza: $(310,0 \pm 3,1) \mathrm{HV}$. 
Quanto a sua microestrutura, a análise feita por microssonda de espectroscopia via EDS em MEV da matriz sem ataque químico, o material apresenta inclusões não metálicas de óxido de alumínio $\left(\mathrm{Al}_{2} \mathrm{O}_{3}\right)$ globulares com tamanho de $(18,0 \pm 1,5) \mu \mathrm{m}$ (confiança de 95\%). Além disso, a microestrutura é formada por ilhas dispersas de ferrita poligonal refinada e bainita acicular em praticamente $100 \%$ da estrutura (Fig. 4).
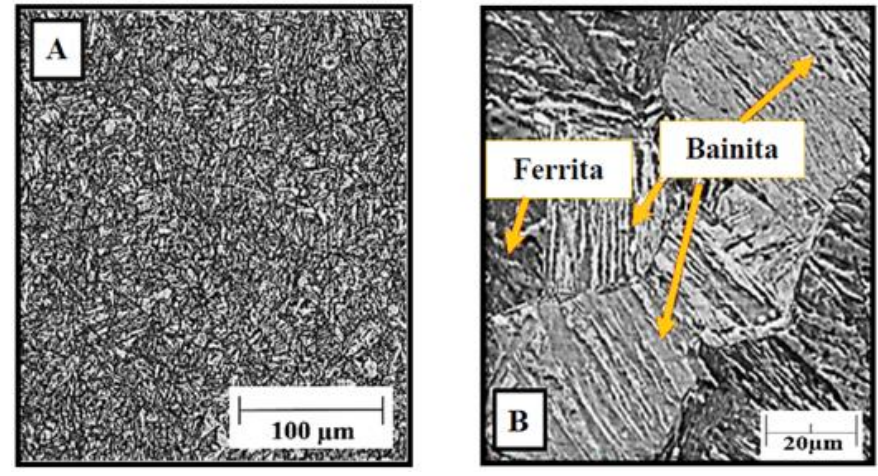

Figura 4: Micrografia em microscópio óptico em “A” (ampliação de 500x) e em MEV em "B” (ampliação de 10000x).

Apesar de os valores de resistência a tração e dureza serem elevados para um material com baixa porcentagem de carbono (fato explicado pelos elementos de liga e pelo processo de fabricação), o alongamento do material mostra considerável ductilidade (possivelmente pela quantidade de ferrita presente em sua microestrutura) com base nos ensaios de tração realizados.

\subsection{Rugosidade da parede do furo}

A Figura 5 apresenta o gráfico com os valores de rugosidade média $\left(R_{a}\right)$ mensurados na entrada e saída dos furos em função das condições de aplicação dos meios lubrirrefrigerantes; abundância, MQL e a seco, utilizando duas brocas: A (sem) e B (com) preparação da mesogeometria (arredondamento).

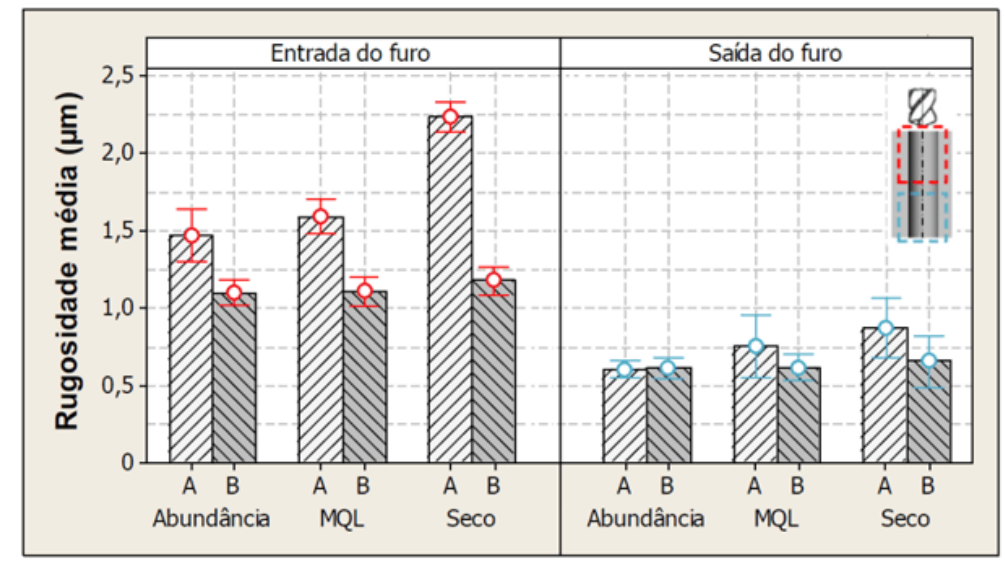

Figura 5: Valores de rugosidade para diferentes meios lubrirrefrigerantes.

Os valores de rugosidade média $\left(\mathrm{R}_{\mathrm{a}}\right)$ apresentados no gráfico representam o resultado da medição de 12 furos realizados para cada condição ferramenta/fluido.

Observa-se que os valores de $\mathrm{R}_{\mathrm{a}}$ foram, em geral, inferiores para as furações realizadas com a broca "B" (com preparação da mesogeometria) em comparação com a broca "A" (sem preparação), principalmente na entrada do furo, independente do meio lubrirrefrigerante utilizado. Nota-se também que a broca "B" gerou valores de rugosidade que não variaram significativamente com o lubrirrefrigerante utilizado. Isto foi comprovado na análise de variância ao nível de confiança de 95\%. Para a broca "A", houve incremento da rugosidade com a diminuição da quantidade de fluido. Em comparação com o fluido em abundância, o aumento foi de aproximadamente 3,5\% para o sistema MQL (estatisticamente, esta variação não foi significativa) e cerca de $30 \%$ para a furação a seco. Ao nível de confiança de $95 \%$, há variação significativa entre os sistemas (MQL e a seco) para as condições analisadas. Verifica-se também que os valores de $\mathrm{R}_{\mathrm{a}}$ são maiores na entra- 
da que na saída dos furos, que os valores na saída dos furos estatisticamente não se alteram ao nível de confiança de $95 \%$ (independente da broca e do meio lubrirrefrigerante), e que as condições a seco e com MQL apresentam resultados significativamente iguais para ambas as brocas na entrada dos furos. Para um entendimento dos fenômenos que contribuíram para tais diferenças ou semelhanças nos valores de $\mathrm{R}_{\mathrm{a}}$, faz-se necessária uma avaliação mais criteriosa da textura da superfície usinada, como mostram as imagens das Figuras 6 e 7 .

A Figura 6 mostra imagens das superfícies usinadas nas entradas dos furos captadas utilizando MEV. Percebe-se que as texturas da superfície apresentam características distintas entre si. Os furos com as brocas "A" e "B" com aplicação de fluido de corte em abundância praticamente não apresentam material aderido na superfície. No caso, a ação lubrificante do fluido nas interfaces peça/broca/cavaco pode facilitar o corte, auxiliar o deslizamento do cavaco e reduzir sua adesão na parede do furo. Os sulcos observados nestas regiões são provavelmente decorrentes das marcas de avanço da broca. Já os furos com as brocas "A" e "B" em $\mathrm{MQF}$ e a seco apresentam textura irregular com material aderido em pequenas regiões na superfície (contornadas pelas linhas tracejadas em vermelho), com variação de quantidade deste material com a restrição do fluido. Um aço como o ARBL submetido a altas pressões e temperaturas em condições com pouca ou nenhuma lubrificação propicia que partes do cavaco fiquem aderidos na entrada dos furos. Diferentemente do que se observou nas imagens dos furos realizados com a broca "A", em que o material aderido localizou-se em pequenas regiões, nos furos efetuados com a broca "B" o material "caldeado" plastificou-se em praticamente toda a região analisada na condição a seco e em algumas regiões com MQL. Este material depositado criou uma nova área de contato sobreposta à parede do furo, praticamente lisa, com poucas marcas de reentrâncias e irregularidades. Isto explica a redução dos valores de rugosidade e a pequena variação de $\mathrm{R}_{\mathrm{a}}$ entre os meios lubrirrefrigerantes.

A adesão de maior quantidade de material pode ter sido influenciada pelo fato de a mesogeometria da broca "B" ter um arredondamento das interseções entre face/flanco, face/quina e raios de quinas, o que pode contribuir para a modificação da mecânica do corte, aumentando as tensões de compressão à frente do gume e promovendo deformações plásticas acentuadas. $\mathrm{O}$ fato de este arredondamento apresentar um fator de forma $\mathrm{K}<1$ significa dizer que há uma tendência ao escoamento do cavaco em alta temperatura e alta pressão sob a superfície de folga $(\mathrm{A} \alpha)$ da broca, sendo pressionado e plastificado contra a superfície usinada, deixando a parede do furo com superfície menos irregular e reduzindo os valores de $\mathrm{R}_{\mathrm{a}}$. Isso não foi constatado na utilização da broca "A" na condição de aplicação de fluido de corte em abundância (salvo nas condições de furação com MQF e a seco, em que o material ficou aderido em pequenas regiões).

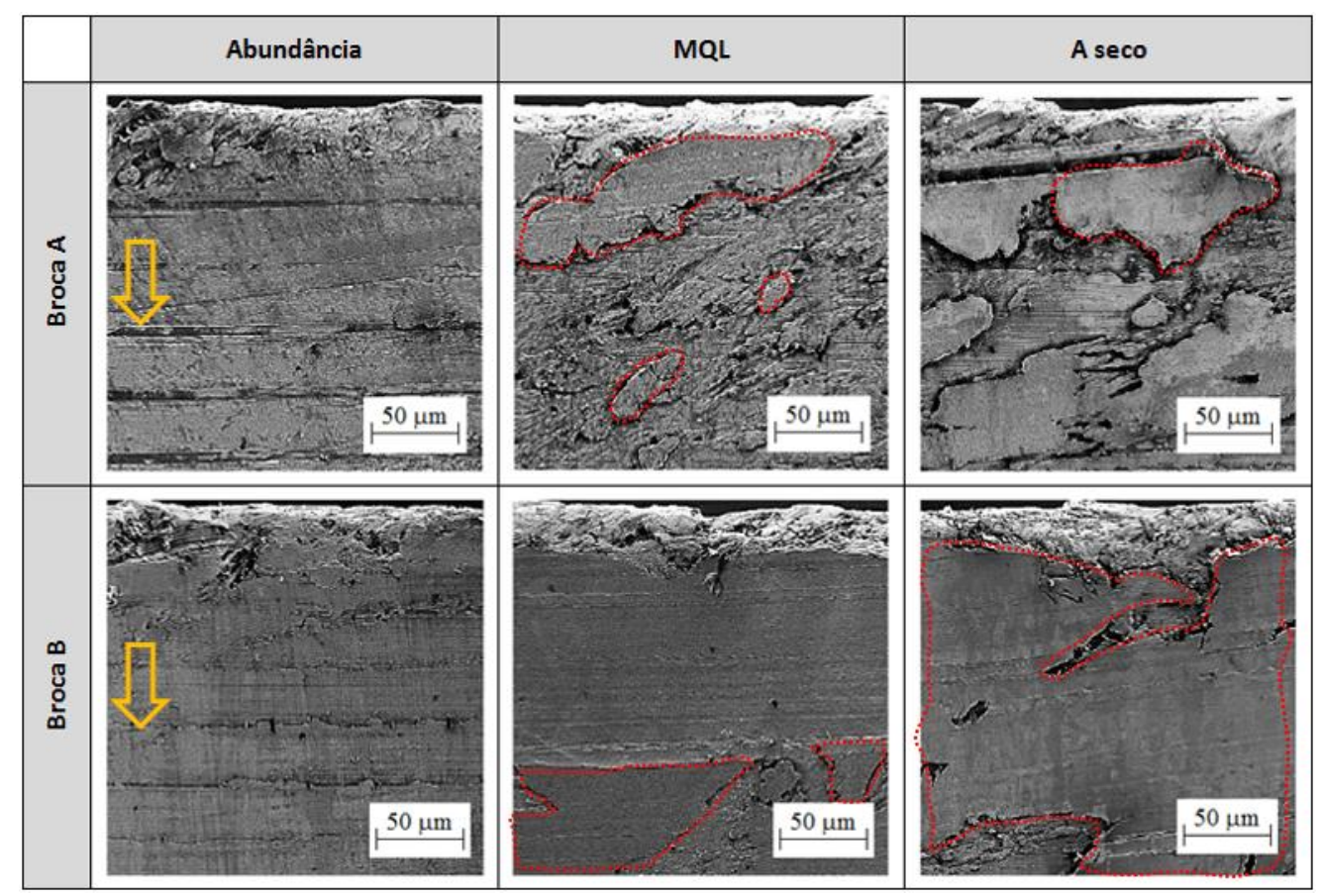

Figura 6: Superfície usinada na entrada dos furos (ampliação 500x). As setas amarelas indicam o sentido de avanço da broca. As linhas tracejadas em vermelho indicam o material aderido (caldeado) sobre a superfície do furo. 
A Figura 7 exibe as imagens das superfícies usinadas nas saídas dos furos obtidas com auxílio do MEV. As imagens estão agrupadas por broca e condição de lubrirrefrigeração.

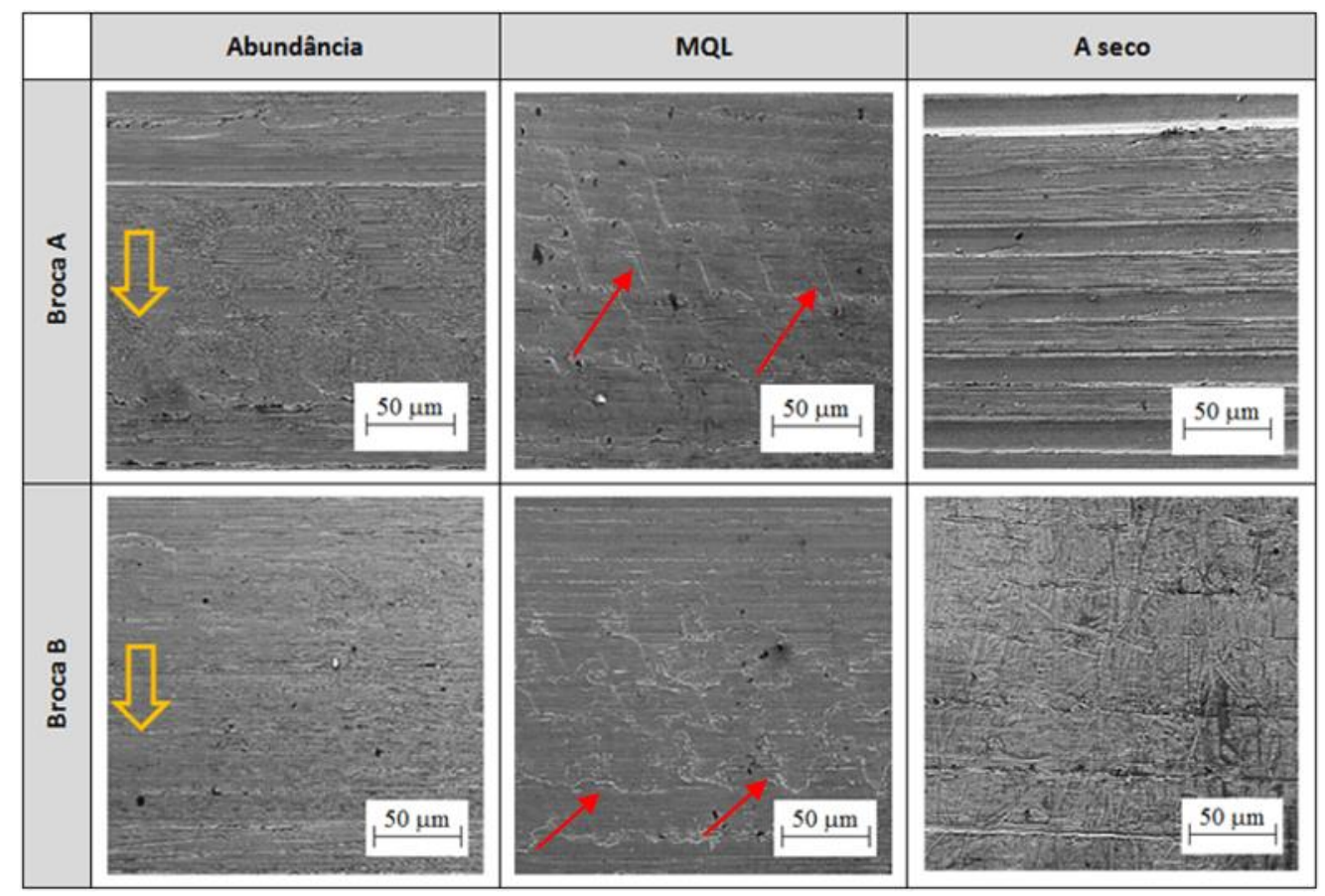

Figura 7: Superfície usinada na saída dos furos (ampliação 500x). As setas amarelas indicam o sentido de avanço da broca. As setas vermelhas apontam a zona de escorregamento com fluxo irregular de material deformado.

Observa-se na Figura 7 que as texturas das superfícies usinadas são distintas a um nível microscópico. Verifica-se também que o material deformado plasticamente não fica aderido à parede próximo à saída do furo, mas escoa para fora, formando rebarbas (ver Fig. 8).

As imagens dos furos gerados com as brocas "A" e "B" na condição de fluido em abundância não mostram influência da geometria da broca (com e sem preparação da mesogeometria). Com relação à homogeneidade da superfície usinada, isto se deve a uma maior facilidade de lubrificação nas interfaces peça/broca/cavaco, o que favorece o corte do material pela broca e o deslizamento do cavaco.

Nos furos com as brocas "A" e "B" na condição com MQL, observam-se marcas características de aderência e arrastamento de material na superfície usinada (zona de escorregamento com fluxo irregular de material deformado). Como o ARBL DIN S700MC pode apresentar inclusões duras e abrasivas de $\mathrm{Al}_{2} \mathrm{O}_{3}$, fragmentos microscópicos podem ter sido arrancados da parede do furo e arrastados junto ao fluxo de material adjacente à interface peça/broca. Isto pode estar associado com as menores eficiências de refrigeração e lubrificação em comparação ao fluido de corte em abundância.

Na condição de furação a seco, o furo com a broca "A" apresenta marcas mecânicas acentuadas, uniformes e alinhadas transversalmente, características de abrasão. Este fato pode estar relacionado com o efeito combinado das marcas de avanço com o atrito entre as quinas da broca e a parede do furo. Nesta condição, a temperatura pode ajudar de forma significativa, reduzindo a resistência ao cisalhamento do material. No caso, as inclusões de $\mathrm{Al}_{2} \mathrm{O}_{3}$ do material-base podem favorecer a formação dos sulcos por abrasão. Já com a broca "B", a deformação plástica, favorecida pelos gumes arredondados, pode ter influência direta na redução dos sulcos decorrentes da passagem da broca pelo furo. Como nesta condição existe a probabilidade de ocorrer deformação plástica lateral, o cavaco tende a ser empurrado contra a parede do furo, minimizando os sulcos decorrentes da passagem da ferramenta formando uma superfície mais uniforme.

De maneira geral, a saída da ferramenta apresentou pouca influência na textura da superfície dos furos. Esse fato pode ser explicado pela pouca resistência mecânica do material (a ser cortado) após a saída do gume transversal devido à área de sustentação na frente dos gumes ser reduzida. Correlacionado a isto, o tempo de contato (atrito) das guias/quinas com a parede do furo é inferior em relação à entrada do furo, o qual permanece em contato com as guias da broca durante todo tempo de usinagem. Este menor tempo de interação entre as partes cortantes e a parede do furo contribui para que o fenômeno de arrastamento de mate- 
rial seja minimizado e os valores de rugosidade sejam semelhantes em praticamente todas as condições analisadas.

\subsection{Medições da rebarba gerada pelo processo de furação}

A caracterização dimensional da rebarba é uma forma de avaliar e uma tentativa de entender os fenômenos gerados durante o processo de corte. A correta análise de sua ocorrência pode ser uma informação importante na tentativa de minimizar efeitos, reduzindo assim os custos de produção e os acidentes com operadores.

Nas condições analisadas não foram identificadas projeções de rebarba na entrada dos furos. Isto pode ter sido influenciado pela deformação provocada pela broca na superfície de entrada durante a penetração devido a uma tendência de deformação ou de o fluxo plástico do material acompanhar o sentido do movimento de avanço da broca, o que pode impedir a geração de projeções salientes para fora do furo.

A alta ductilidade do aço ARBL DIN S700MC favorece a geração das rebarbas, a qual segue o movimento de avanço da broca. A Figura 8 ilustra a forma da rebarba gerada após o processo de furação na saída da broca no corpo de prova utilizando MEV com aumento de 100x. Para as condições analisadas, o tipo e a forma das rebarbas foram semelhantes, diferenciando apenas na dimensão da altura.

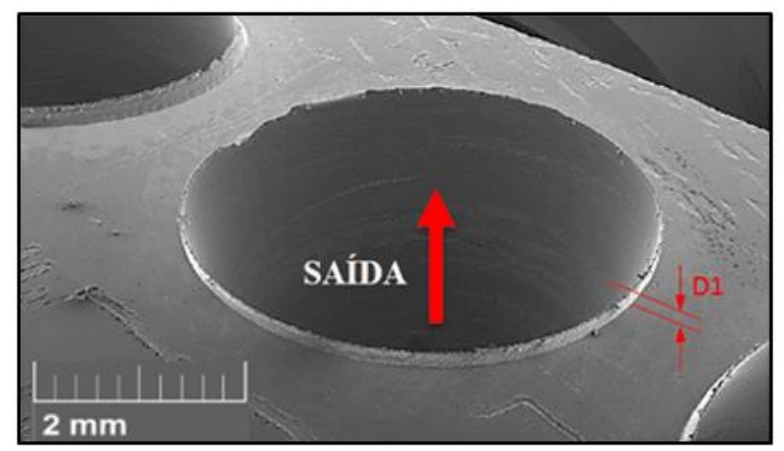

Figura 8: Topografia geral da rebarba gerada pelo processo de furação.

No gráfico da Figura 9 observa-se um incremento nos valores médios da altura da rebarba nos furos realizados com a broca "B" (com preparação) em relação aos valores com a broca "A" (sem preparação).

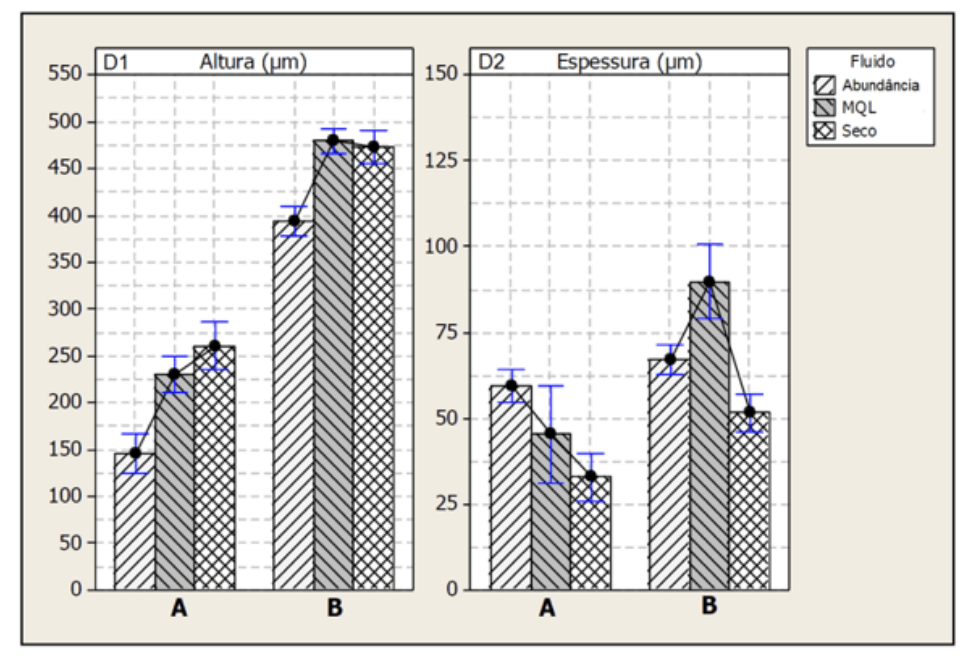

Figura 9: Valores médios da altura (D1) e espessura da raiz (D2) das rebarbas.

Na avaliação dos furos realizados com a broca "A" (Fig. 9), observa-se que houve um aumento dos valores médios da altura da rebarba (referência D1) com a crescente restrição do fluido de corte (de abundância para MQL e depois a seco). Já para a broca "B", o comportamento foi ligeiramente distinto. Neste caso, prevaleceu a aplicação do fluido em abundância como condição de geração da menor altura D1; ademais, a condição de MQL e a seco apresentaram similaridade entre si (para um nível de confiança de 95\%), pois a aplicação de fluido de corte em abundância se beneficia das funções primárias de lubrificação e refrigeração, 
reduzindo assim o atrito e a temperatura na região de corte. Estes decréscimos fazem com que o escoamento do material (deformação plástica) não seja muito acentuado na condição em abundância, contribuindo assim para que haja uma redução dos valores de altura D1.

Em relação à espessura da raiz da rebarba (referência D2), não se pode afirmar que o meio lubrirrefrigerante afeta significativamente seu valor (confiança de 95\%). No entanto, a broca "B" gerou valores maiores de D2, os quais podem novamente ter sido influenciados pela maior deformação plástica do material promovida pela alteração mesogeométrica da broca, resultando em maior quantidade de material escoado no mesmo sentido de movimento da broca, aumentando assim a espessura na região da raiz da rebarba.

\subsection{Medições da camada afetada pelo calor}

A avaliação da extensão da camada afetada pelo calor (CAC) promove a ideia da severidade do processo de corte e possibilita a quantificação destes valores. Tais informações são relevantes para o entendimento dos efeitos causados durante a furação com a utilização de diferentes condições de usinagem.

A Figura 10 ilustra o gráfico dos valores médios das larguras mensuradas ao longo da superfície transversal ao furo, considerando as duas brocas (A e B) e as diferentes condições de aplicação dos meios lubrirrefrigerantes utilizados. As análises foram realizadas na entrada, no meio e na saída dos furos. Pode-se notar que a broca "A" (sem preparação mesogeométrica) gerou uma largura de CAC inferior em relação aos furos realizados com a broca "B" (com preparação).

Como supracitado, a condição de arredondamento dos gumes modifica a ação de corte da ferramenta, fazendo com o cisalhamento do cavaco não ocorra de maneira adequada (aumenta a deformação à frente do gume e, consequentemente, aumenta o calor gerado).

Avaliando os resultados da Figura 10, percebe-se que com a utilização da broca "A", a condição a seco apresentou os maiores valores de CAC; já o sistema MQL e aplicação de fluido de corte em abundância apresentaram os menores valores de CAC e foram estatisticamente similares entre si a um nível de confiança de $95 \%$. Apesar de não haver diferença significativa entre os valores (sistema MQL e de fluido em abundância), os gerados com MQL para a broca "A" são ligeiramente superiores. Como mencionado previamente, o fluido em abundância se beneficia de suas funções primárias, auxiliando na redução do atrito entre a bro$\mathrm{ca} /$ cavaco/peça, da temperatura e das deformações locais. Já o sistema MQL apresenta menor efetividade de refrigeração do sistema, o que pode ter contribuído para este pequeno incremento da largura da CAC. Consequentemente, na furação a seco, os maiores valores da CAC podem ser justificados pela ausência das funções primárias do fluido de corte.

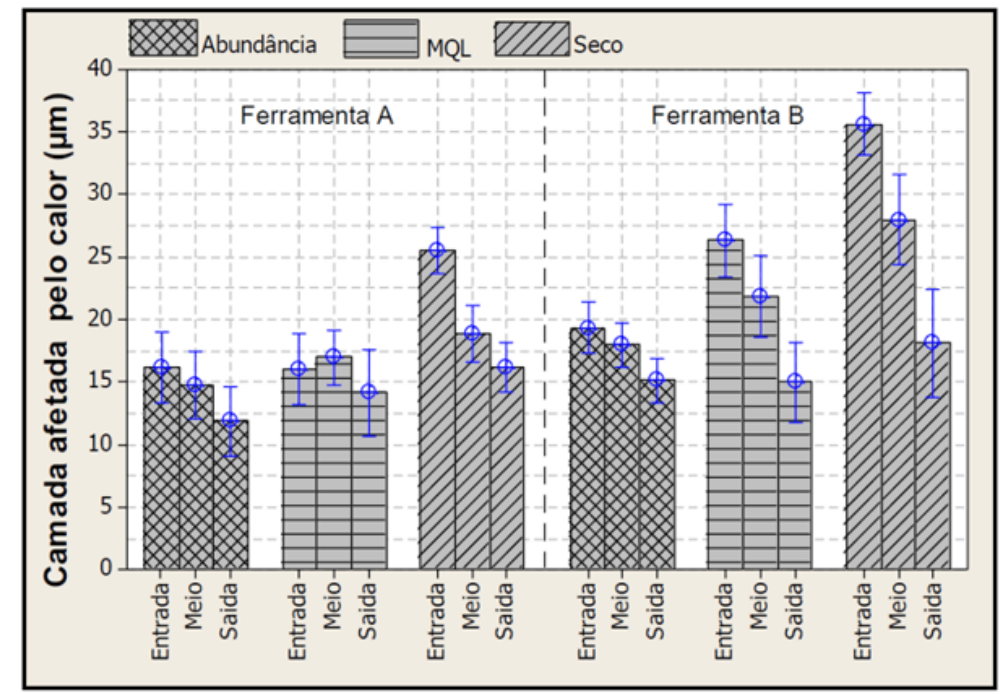

Figura 10: Valores médios da largura da camada afetada pelo calor (CAC).

Analisando a broca "B" observa-se que apesar de os valores não apresentarem diferenças significativas (confiança de 95\%), tem-se que a largura da CAC aumenta sensivelmente com a redução proporcional de lubrirrefrigeração (abundância, MQL e a seco) pelos mesmos motivos descritos para a broca "A".

Com exceção da utilização da broca " $A$ " aplicando MQL, percebe-se também que houve uma diminuição expressiva dos valores médios da largura da CAC da entrada para a saída dos furos. Tal redução pode 
ter sido influenciada pela maior interação (atrito) entre a ferramenta/cavaco/peça na entrada do furo. Este atrito contribui para um aumento da temperatura de corte, reduzindo a resistência mecânica, o que facilita o fluxo plástico do material devido à força de penetração da ferramenta. A broca em contato com o cavaco em temperatura e pressão elevadas pode contribuir para modificações microestruturais nesta região.

Assim, para avaliar se ocorreram tais modificações que justificassem as alterações nos valores medidos de CAC, foram realizadas micrografias na superfície secionada dos furos. A Figura 11 mostra estas regiões, onde a linha traço-ponto representa a largura da CAC em cada região do furo analisado. Não há indicativos de mudança de fase nesta região e sim encruamento do material em virtude de severidades térmicas e mecânicas que o corpo de prova foi submetido durante o processo de furação. As imagens foram realizadas com o auxílio de MEV com ampliação de 3000x e detector de elétrons retroespalhados (BSE - Backscattering Electron).

Pela quantidade de imagens geradas e pelas similaridades entre si das mesmas, a Figura 11 apresenta apenas o furo obtido na condição a seco em virtude de esta ser a mais severa dentre as condições analisadas. As imagens foram realizadas nas posições de entrada, meio e saída dos furos para as brocas " $A$ ” e " $B$ ".

$\mathrm{Na}$ medida em que broca segue o movimento de avanço até vencer a espessura total da peça, a guia/quina da ferramenta continua gerando altas temperaturas de corte ao longo do furo. Porém, quando o gume transversal rompe o centro do furo, pelo fato de o material oferecer uma resistência mecânica reduzida pela menor área do material abaixo da broca, a temperatura diminui. $\mathrm{O}$ atrito entre a broca e a peça, na condição de saída, pode ser considerado menor, pois não há mais interação entre a broca e a peça no instante em que a guia consegue romper a espessura total da chapa. Porém, na entrada do furo, as guias ainda estão em contato com a superfície, favorecendo a variação da microestrutura.

\section{DISCUSSÃO}

\subsection{Rugosidade da parede do furo}

Para a broca "A", o fato de as furações com fluido de corte em abundância apresentarem resultados inferiores de rugosidade média $\left(R_{a}\right)$ pode ser resultado da redução do atrito nas interfaces broca/cavaco e broca/parede do furo, bom arrefecimento, além de permitir que o cavaco escoe com mais facilidade para fora do furo [13, 15]. No caso do MQL, os resultados foram similares. Apesar de o MQL apresentar certa deficiência na refrigeração, que praticamente é feita pelo ar comprimido (não garante uma boa eficiência), a lubrificação é mantida pelo óleo do sistema (MQL), que neste caso foi mantido próximo à entrada do furo através de um bico externo. Este óleo pode se aderir na superfície da parede do furo, formando um filme fino que provavelmente reduz o atrito da broca nas interfaces, facilita o escoamento do cavaco para fora do furo e, por conseguinte, reduz os valores de rugosidade. Este mesmo fenômeno foi descrito por BORDIN e ZEILMANN [6], onde na furação de um aço P20, os valores de rugosidade foram reduzidos com a utilização do sistema de MQL em comparação à aplicação de fluido em abundância. 


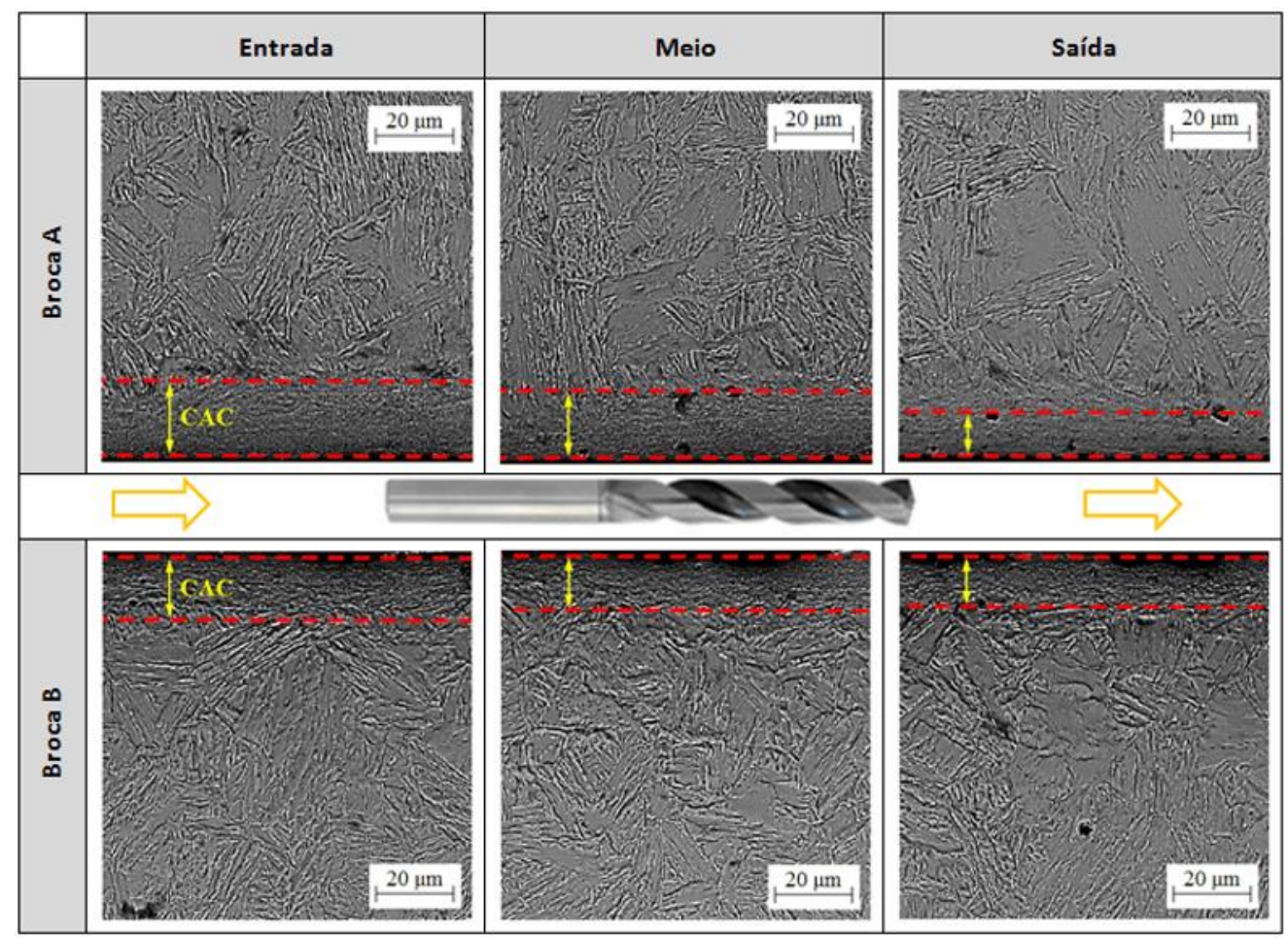

Figura 11: Representação da camada afetada pelo calor (CAC) para as brocas "A" e "B" na furação a seco.

O fato foi explicado pela microlubrificação aplicada próximo à região de corte, associado com o cisalhamento facilitado pelo aumento da temperatura, o que reduziu as forças de corte e contribuiu com a redução dos valores de rugosidade. Já na furação a seco, os valores de $\mathrm{R}_{\mathrm{a}}$ foram os mais elevados, pois segundo COSTA et al. [16] e ZEILMANN et al. [17], a eliminação total do fluido representa um aumento da temperatura de corte, maior atrito e maior desgaste da ferramenta, podendo ser desfavorável ao acabamento da superfície.

$\mathrm{O}$ arredondamento do gume potencializa o efeito ploughing no processo de usinagem. Este efeito significa que parte do material deformado na frente da cunha tenderá a escoar plasticamente para os lados do gume. Assim, a remoção do material formará rebarbas que deformarão lateralmente, aumentando a possibilidade de o cavaco ser empurrado contra a superfície usinada $[14,18]$.

BORDIN e ZEILMANN [6] explicam que a textura da superfície usinada com caldeamento de material mostra que houve uma ação deficiente de lubrificação, a qual proporciona o aumento do atrito entre as guias da broca e a parede do furo, promovendo um aquecimento demasiado do cavaco. Este material aquecido é pressionado pelas guias da broca, aderindo-se à superfície do furo o que é, segundo os autores, extremamente crítico (em se tratando de peças de responsabilidade) devido à formação de elevadas tensões residuais. Este fenômeno não pode ser identificado pela medição de parâmetros de rugosidade, pois o material depositado na parede do furo fica sobre os sulcos deixados pela ferramenta, "mascarando" os resultados. Destarte, para uma eficiente análise, necessita-se preparar a amostra (metalografia) para sua visualização por microscopia óptica.

\subsection{Medições da rebarba gerada pelo processo de furação}

O fluxo plástico de material para fora do furo no sentido de avanço da broca também foi descrito por COSTA et al. [16]. A rebarba formada na saída dos furos é uniforme ao longo de todo o perímetro do furo. Com isto, segundo AURICH et al. [19], esta rebarba se enquadra como Tipo II (chapéu).

Resultados semelhantes foram descritos por MONDAL et al. [20] na furação de um aço baixa liga com dureza média de 225 HB utilizando broca de aço-rápido e aplicando fluido de corte em abundância e a seco. Concluíram que o dimensional da rebarba gerada no furo diminui significativamente com a utilização de fluido de corte. Assim, no corte a seco, tem-se uma maior temperatura, a qual facilita a deformação plástica e promove o escoamento do material para fora dos furos resultando em maiores valores de rebarba. 
Já o fato de a broca "B" gerar as maiores alturas das rebarbas nos furos pode ter sido consequência dos gumes arredondados, o que modifica a mecânica do corte; com isto, tem-se uma deformação plástica acentuada à frente dos gumes com provável aumento da temperatura. DAVIM [21] cita que o cisalhamento de um material com alta ductilidade fica facilitado quando da utilização de ferramentas com gumes afiados.

\subsection{Medições da camada afetada pelo calor}

Na furação de uma liga à base de níquel, KWONG et al. [22] descrevem a modificação microestrutural da entrada à saída da broca com magnificações distintas. Os autores identificaram esta variação como sendo uma deformação plástica radial (DPT) em consequência do tempo superior de contato entre a ferramenta (quina/guia) com o cavaco recém-formado na entrada dos furos, se comparado com o tempo de permanência nas guias com o cavaco na saída da ferramenta.

\section{CONCLUSÕES}

A preparação dos gumes da broca helicoidal de metal-duro com revestimento de TiAlN e as condições de lubrirrefrigeração utilizadas apresentam efeitos significativos sobre o acabamento da parede dos furos realizados no aço ARBL DIN S700MC.

- Os valores de $\mathrm{R}_{\mathrm{a}}$ obtidos com a broca "A" (sem alteração mesogeométrica) utilizando mínima quantidade de lubrificante (MQL) foram similares aos obtidos com fluido de corte em abundância.

- A broca "B" (com alteração mesogeométrica) promove maior deformação plástica do material à frente do gume arredondado. Isto gera alturas e espessuras das raízes da rebarba Tipo II (chapéu) na saída do furo com valores superiores aos gerados pela broca "A" (com gume afiado).

- As funções primárias do fluido de corte reduzem o escoamento do material. Assim, para a broca "A" (afiada), a altura da rebarba aumenta e a espessura da raiz da mesma diminui com a redução do efeito lubrirrefrigerante. Para a broca "B", o sistema MQL gerou os piores resultados.

- A camada afetada pelo calor (CAC) gerada foi maior com a broca "B" e aumenta à medida que se restringe a aplicação do fluido lubrirrefrigerantes proporcionalmente (abundância, MQL e a seco).

- As aplicações de fluido de corte em abundância e em MQL demostram resultados similares em relação à largura da CAC gerada pela broca " $A$ ".

- A utilização de MQL torna-se novamente vantajosa quando a broca "A" é aplicada.

\section{AGRADECIMENTOS}

Os autores agradecem as respectivas empresas pelo suporte técnico de máquina-ferramenta (Indústrias ROMI S.A), brocas (Sandvik Coromant), corpos de prova (PCP Produtos Siderúrgicos) e fluidos de corte (Blaser Swisslube do Brasil e Castrol Brasil).

\section{BIBLIOGRAFIA}

[1] GORNI, A.A. "Aços avançados de alta resistência: microestrutura e propriedade mecânicas", Corte $e$ Conformação de Metais, v. 44, n. 4, pp. 26-57, Dez. 2008.

[2] SIVARAMAN, V., SANKARAN, S., VIJAYARAGHAVAN, L. "A study on the influence of cutting parameters on forces during machining the multiphase V-microalloyed steel", The International Journal of Advanced Manufacturing Technology, v. 79, n. 5, pp. 1285-1292, July 2015.

[3] CALliSTER, W., WILliAM D. Ciência e Engenharia de Materiais: Uma Introdução, 2 ed., Rio de Janeiro, LTC, 2012.

[4] KLOCKE, F. Manufacturing Processes 1: Cutting, 1 ed., Berlin Heidelberg, Springer-Verlag, 2011.

[5] BASAVARAJAPPA, S., CHANDRAMOHAN, G., PRABU, M., et al., "Drilling of hybrid metal matrix composites - workpiece surface integrity", International Journal of Machine Tools and Manufacture, v. 47, n. 1, p. 92-96, Jan. 2007.

[6] BORDIN, F.M., ZEILMANN, R.P., "Effect of the cutting edge preparation on the surface integrity after dry drilling", Procedia CIRP, v. 13, pp. 103-107, 2014. 
[7] TUSSET, F., CONSALTER, L.A., DURÁN, O., "The effects of microgeometries in carbide twist drill on dry drilling of cast iron", The International Journal of Advanced Manufacturing Technology, v. 87, n. 9, pp. 3123-3135, Dec. 2016.

[8] BIERMANN, D., DENKENA, B., "Cutting edge geometries”, CIRP Annals - Manufacturing Technology, v. 63, n. 2, pp. 631-653, 2014.

[9] FULEMOVA, J., ZDENĚK, J., "Influence of the cutting edge radius and the cutting edge preparation on tool life and cutting forces at inserts with wiper geometry", Procedia Engineering, v. 69, pp. 565-573, 2014.

[10] VENTURA, C. E. H., DENKENA, B., "Preparação de arestas de ferramentas de cerâmica mista por retificação e sua aplicação no torneamento de aço endurecido", In: $8^{\circ}$ Congresso Brasileiro de Engenharia de Fabricação, Salvador, BA, Brasil, 18-22 maio 2015.

[11] LAWAL, S.A., CHOUDHURY, I.A., NUKMAN, Y., “Application of vegetable oil based metal working fluid in machining ferrous metals - a review", International Journal of Machine Tools and Manufacture, v. 52, n. 1, pp. 1-12, Jan. 2012.

[12] ZHANG, S., LI, J.F., WANG, Y.W., "Tool life and cutting forces in end milling Inconel 718 under dry and minimum quantity cooling-lubrication cutting condition", Journal of Cleaner Production, v. 32, pp. 8187, Sept. 2012.

[13] BURTON, G., GOO, C.S., ZHANG, Y., JUN, M.B.G., "Use of vegetable oil in water emulsion achieved through ultrasonic atomization as cutting fluids in micro-milling", Journal of Manufacturing Processes, v. 16, n. 3, pp. 405-413, Aug. 2014.

[14] MACHADO, A.R., ABRÃO, A.M., COELHO, R.T., et al., Teoria da Usinagem dos Materiais, 2 ed., São Paulo, Blucher, 2011.

[15] RODRIGUES, J.R.P., NEVES, T.E.S.B., SILVA, M.B., et al., "Study of the application of sunflower oil in the process of drilling ABNT 1045 steel", Acta Scientiarum. Technology, v. 36, n. 2, pp. 257-262, Apr.June 2014.

[16] COSTA, E.S., SILVA, M.B., MACHADO, A.R, "Burr produced on the drilling process as a function of tool wear and lubricant-coolant conditions", Journal of the Brazilian Society of Mechanical Sciences and Engineering, v. 31, n. 1, pp. 57-63, 2009.

[17] ZEILMANN, R.P., VACARO, T., SOARES, R.M., et al., "Estudo da formação de cavaco na furação a seco do aço AISI P20 endurecido", In: $6^{\circ}$ Congresso Brasileiro de Engenharia de Fabricação, Caxias do Sul, RS, Brasil, 11-15 abril 2011.

[18] BIERMANN, D., IOVKOV, I., BLUM, H., et al., "Thermal aspects in deep hole drilling of aluminum cast alloy using twist drills and MQL", Procedia CIRP, v. 3, pp. 245-250, 2012.

[19] AURICH, J.C., DORNFELD, D., ARRAZOLA, P.J., et al., "Burrs - analysis, control and removal". CIRP Annals - Manufacturing Technology, v. 58, n. 2, pp. 519-542, 2009.

[20] MONDAL, N., BISWAJIT S.S., HALDER, R.N., et al., "Observation of drilling burr and finding out the condition for minimum burr formation", International Journal of Manufacturing Engineering, Hindawi Publishing Corporation, Article ID 208293, 2014.

[21] DAVIM, J.P. Surface Integrity in Machining. 1 ed., London, Springer-Verlag, 2010.

[22] KWONG, J., AXINTE, D.A., WITHERS, P.J., et al., "Minor cutting edge - workpiece interactions in drilling of an advanced nickel-based superalloy", International Journal of Machine Tools and Manufacture, v. 49, n. 7-8, pp. 645-658, June 2009.

\section{ORCID}

Luiz Eduardo da Silva

https://orcid.org/0000-0002-2295-4118

Luiz Airton Consalter

https://orcid.org/0000-0003-2409-6134

William Haupt

https://orcid.org/0000-0002-8267-1611

André João de Souza

https://orcid.org/0000-0001-5649-7333 